\title{
MOVIMENTOS DE LUTA PELA TERRA NO NORTE DO RS: O ACAMPAMENTO CAPÃO DA CASCAVEL NA FAZENDA SARANDI (1960/62)
}

\author{
Land fighting movements in northern RS: \\ Capão da Cascavel camp at Fazenda Sarandi - 1960-62
}

\author{
João Carlos Tedesco ${ }^{1}$ \\ Joel João Carini ${ }^{2}$
}

\begin{abstract}
RESUMO
O artigo analisa o contexto onde se desenvolveram as ações do Movimento dos Agricultores Sem Terra (Master) no norte do Rio Grande do Sul. Centraliza o foco no acampamento Capão da Cascavel por ter sido central do movimento social e cenário de grande expressão das contradições da propriedade de terra. Utilizam-se referências bibliográficas, documentos e notícias de jornais para fundamentar a importância do acampamento. $\mathrm{O}$ movimento dos agricultores condensou um contexto efervescente nas demandas e pressões pela terra, envolveu múltiplas instituições e a centralidade da esfera pública no governo de Brizola. As ações do governo em prol da reforma agrária foram fundamentais para dar sequência a esse processo na história dos movimentos da luta da terra pelos pequenos agricultores e indígenas.
\end{abstract}

Palavras-chave: Master; Reforma agrária; Governador Brizola.

\begin{abstract}
The article analyzes aspects of the context in which some of the actions of the Landless Farmers Movement (Master) in the north of Rio Grande do Sul were developed; centralizes its focus on Capão da Cascavel Camp for having been central to the actions of said social movement and in a
\end{abstract}

1 É professor titular da Universidade de Passo Fundo - PPGH/UPF. Pós-doutor em História Contemporânea pela Universidade de Milão. E-mail: jctedesco@upf.br.

2 Doutor em Desenvolvimento Rural pela Universidade Federal do Rio Grande do Sul - UFRGS. É professor do ensino básico técnico e tecnológico do Instituto Federal Farroupilha - Campus Frederico Westphalen. E-mail: joel.carini@iffarroupilha.edu.br. 
scenario of great expression of the contradictions of the ownership of the land in the southern state. It uses bibliographical references, documents, and news from newspapers to substantiate the importance of said camp; concludes that the Master condensed an effervescent context of demands and pressures for the land, involved multiple institutions, but with the centrality of the public sphere personified in the governor Brizola. We conclude that the actions of the governor in favor of agrarian reform were fundamental to the sequence of this process in the history of the struggles for land by small farmers and indigenous people.

Keywords: Master; Land reform; Governo Brizola.

\section{Introdução}

A ascensão de João Goulart à Presidência, após a renúncia de Jânio Quadros em 1961, pôs fim à aliança populista entre PTB e PSD. As "Reformas de Base" 3 anunciadas por Jango assustaram os conservadores, principalmente a elite agrária nacional, contrária à reforma agrária.

O governo Brizola (PTB) enfrentava forte oposição do PSD, que defendia os interesses da elite agrária. Da outra parte, Brizola recebia ampla adesão da maioria do operariado urbano e dos pequenos agricultores. A campanha vitoriosa do movimento da Legalidade de agosto de $1961,{ }^{4}$ levantada no Rio Grande do Sul, principal âncora de apoio ao governo Goulart, deu a Brizola status de líder nacional. Assim, no final de 1961 e começo de 1962, Brizola sentia-se fortalecido o bastante para levar a termo o projeto da reforma agrária, uma das principais bandeiras do seu governo.

\footnotetext{
3 Conjunto de medidas anunciadas por João Goulart consideradas necessárias para superar o atraso histórico do Brasil, sair da crise global em que a nação estava mergulhada, integrar as populações marginalizadas na vida nacional e preparar o Brasil para a arrancada rumo ao desenvolvimento. As reformas elencadas eram: Reforma Agrária, Reforma Urbana, Reforma da Empresa, Reforma Partidária e Eleitoral, Reforma Administrativa, Reforma Fiscal e Tributária, Reforma Bancária, Reforma Cambial e Reforma Educacional. Ver BRUM, A. $O$ desenvolvimento econômico brasileiro. 17. ed. Petrópolis: Vozes; Ijuí: Editora Unijuí, 1997. p. 270-271.

4 Movimento liderado por Brizola, governador do estado do Rio Grande do Sul, para defender o regime constitucionalista. O movimento teve forte apoio popular, obteve apoio de outros estados, constituindo-se na chamada "Rede da Legalidade", em agosto de 1961, obtendo apoio, inclusive, do comandante do III Exército, sediado no Rio Grande do Sul. Milhares de pessoas ocuparam a Praça da Matriz, defronte ao Palácio Piratini, expressando apoio e engajamento político. Brizola posicionou-se contra o parlamentarismo, denunciando-o como uma violação à Constituição. Esse processo projetou nacionalmente Brizola como líder popular.
} 
A Igreja Católica também exercia influência muito forte no meio social, principalmente no espaço rural, no que se refere às propostas modernizantes em relação ao trabalho e à produção na terra, porém conservava formas patriarcalistas e assistencialistas nas associações e representações dos camponeses.

Com a fundação de sindicatos e o surgimento de outras agremiações, como os círculos operários, as disputas nesse meio social entre a Igreja Católica, PTB e PCB dinamizaram a esfera política nas décadas de 1950 e 1960 em nível nacional. Os círculos operários, por exemplo, surgiram no início da década de 1930 com a intenção de bloquear o avanço dos partidos marxistas no interior do operariado, exerciam função preparatória na direção em que a Igreja se desenvolvia no interior dos sindicatos, ou seja, a luta contra o comunismo e a construção de um Brasil cristão democrático e desenvolvimentista (RICCI, 1999).

A União dos Lavradores e Trabalhadores Agrícolas do Brasil (Ultab) foi fundada em 1950, tendo como presidente o sindicalista comunista Lindolfo Silva, que seguia a linha do PCB, após 1945, na organização dos trabalhadores no campo. A agremiação entendia ser necessária a reforma da estrutura fundiária no país para diminuir os latifúndios e promover a distribuição de terras aos trabalhadores, ampliando a distribuição de alimentos, barateando o preço dos produtos agrícolas, desenvolvendo forças produtivas atrasadas (CARONE, 1982; CUNHA, 2004).

Várias forças políticas tentaram organizar e controlar o movimento camponês no sentido de adequá-lo aos seus princípios. As ligas camponesas (pioneiras no Nordeste do país e espalhadas no território, se destacaram pela organização, apoio ao associativismo camponês e luta pela reforma agrária), o PCB, a Igreja Católica e uma ala desmembrada, denominada "católicos radicais", todos vinculados à Ação Popular, eram de grande aceitação no meio popular.

Intelectuais progressistas, membros de partidos políticos, o PCB com mais presença (já com longa história na participação social e política na sociedade brasileira no meio urbano, principalmente dos grandes municípios), profissionais liberais adeptos a um processo modernizador e mais justiça social no campo agregaram-se às lutas dos camponeses em várias regiões do país, exigindo reforma agrária, alteração nas estruturas fundiárias e políticas agrícolas, legislação rural adequada à performance dos pequenos produtores, dentre outros, somavam centenas de milhares em todo o Brasil durante a década de 1950 para combater o lado contraditório e atrasado da estrutura agrária. 
Na década de 1950 e início de 1960, revela-se um contexto histórico efervescente no que diz respeito às organizações sociais e políticas relacionadas à questão da terra. Nesse cenário, tomou corpo o Movimento dos Agricultores Sem Terra do Rio Grande do Sul (Master), agregando um amplo espectro de relações, vínculos, contraposições, polêmicas, repressão etc. Foi um movimento pioneiro na questão da luta pela terra no estado, apoiado (pelo menos num período) pelo governador e que produziu delineamentos posteriores na luta pela reforma agrária e políticas deliberadas no interior das reservas indígenas.

O acampamento do Capão da Cascavel no atual município de Sarandi, formado entre 1961 e 1962, foi paradigmático em termos numéricos - mais de dez mil agricultores (RUCKERT, 1991), bem como de expressão pública do Master na luta pela reforma agrária.

Para esta pesquisa foram utilizadas fontes variadas sobre o movimento Master no estado, como jornais regionais (Passo Fundo, em particular), documentos, correspondências enviadas pelo governador Brizola, dentre outras, no afã de compreender o processo ocorrido no acampamento do Capão da Cascavel no norte do Rio Grande do Sul.

Primeiramente, o texto aborda alguns aspectos que configuraram a questão da terra na região Norte onde surgiu o Master; posteriormente, procuraremos demonstrar a centralidade do governador Brizola, os conflitos internos e as posições dos mediadores. No final, abordaremos o acampamento Capão da Cascavel como expressivo nas ações do governador e do próprio movimento Master, bem como alguns desdobramentos. A intenção central da análise é mostrar que esse movimento de Capão da Cascavel condensou um amplo processo de posições, ambiguidades, interpretações e estratégias em torno da reforma agrária no Rio Grande do Sul capitaneada pelo governador Brizola.

\section{Os problemas agrários na região Norte do Rio Grande do Sul-décadas de 1950-60}

É importante destacar que o norte do Rio Grande do Sul foi um dos últimos espaços colonizados no estado. No início do século XX, essa região foi válvula de escape da pressão social existente nas áreas de 
colonização anterior, marcadas por um intenso retalhamento das glebas familiares, passando a absorver grande contingente de pequenos agricultores que não possuíam terra suficiente para sua sobrevivência em consequência da fragmentação da família ocasionada por novos casamentos. $\mathrm{O}$ avanço da colonização promoveu a extinção de pequenas posses situadas em terras de matas ou campos adjacentes e forçou a demarcação de reservas indígenas na tentativa de resguardar, ainda que parcialmente, os seus territórios. Num segundo momento, nem mesmo as reservas foram respeitadas, ocorrendo a ocupação em conivência com o Estado (ZARTH, 2002).

Na década de 1950, a estrutura fundiária começou a ser redesenhada em razão das novas possibilidades de extração econômica da terra. Em termos de estruturação fundiária, a região refletiu os grandes processos que objetivaram a concentração de áreas de terras em poucas mãos e a proliferação de pequenas propriedades com área insuficiente para a sobrevivência (GREGORY, 2002). A economia do trigo e da extração da madeira, tão evidentes na primeira metade do século XX, associaram-se; sua modernização técnica exigia grandes extensões; proliferaram também os pequenos proprietários, que aos poucos, marginalmente ou não, foram induzidos a se inserirem nos canais da modernização produtiva sob a égide da lógica do excedente de mercado mediado por comerciantes (RUCKERT, 1991; ZARTH, 2002).

No decorrer das décadas de 1950 e 1960, a agricultura tradicional, que vinha sendo praticada até então, não conseguia mais corresponder às necessidades dos agricultores, razão pela qual muitos, desestimulados, empobrecidos, migraram para regiões do Paraná e oeste de Santa Catarina, explorando novas áreas de mata. Pesavento descreve a situação do pequeno agricultor dizendo:

[...] o baixo nível técnico dos minifúndios limitava a produtividade e vinha associar-se a uma política de baixos preços para os produtos agrícolas, imposta pelo capital comercial/ industrial. As máquinas se apresentavam muito caras para os pequenos proprietários, que não tinham condições de obter crédito fácil para poder adquiri-las. Além de tais problemas, a crescente concentração da propriedade das terras no estado limitava as chances de expansão da área agrícola policultora. 
O Rio Grande, nos anos 50, apresentava-se como o estado que mais população emigrante fornecia para outros estados, enquanto que era também a unidade da federação que menos brasileiros recebia (PESAVENTO, 1982, p. 124).

Do final da década de 1950 até a segunda metade da década de 1960, ocorreu na região a consolidação do arrendatário em proprietário fundiário. Fases posteriores, que transcenderam nossa temporalidade de análise, foram marcadas com a presença e a consolidação do modelo produtivista, intensificado pela dinâmica do crédito subsidiado (seletivo e regionalizado), com a forte ação do Estado por meio de políticas públicas; outros períodos foram marcados pela retração do crédito e pela forte inserção dos complexos agroindustriais.

Desse modo, o surgimento dos "sem terras" está ligado à penetração do capitalismo no campo, responsável por um processo contínuo de concentração da propriedade e de substituição da mão de obra braçal pela introdução de pacotes tecnológicos cada vez mais avançados. Além de provocar um impacto direto na mão de obra, as novas técnicas submeteram contingentes cada vez maiores de pequenos agricultores a um contínuo processo de descapitalização.

Tabela 1 - Número de estabelecimentos rurais de área (ha) no centro do planalto rio-grandense de 1940 a 1970.

\begin{tabular}{c|c|c|c|c|c|c}
\hline & \multicolumn{2}{|c|}{ Pequenos } & \multicolumn{2}{c|}{ Médios } & \multicolumn{2}{c}{ Grandes } \\
\hline Anos & $\mathbf{N}^{\mathbf{0}}$ estab. & Área & $\mathbf{N}^{\mathbf{0}}$ estab. & Área & $\mathbf{N}^{\mathbf{0}}$ estab. & Área \\
\hline 1940 & 9.835 & 218.804 & 2.359 & 259.806 & 191 & 182.306 \\
1950 & 15.110 & 306.235 & 2.784 & 297.375 & 192 & 222.353 \\
1960 & 19.144 & 353.854 & 2.736 & 280.884 & 143 & 212.700 \\
1970 & 25.336 & 420.296 & 2.855 & 316.312 & 167 & 160.589 \\
\hline
\end{tabular}

Fonte: IBGE, 1940, 1950, 1960 e 1970, adaptado de Rückert, A., op. cit., 1991.

No Rio Grande do Sul, segundo Ohlweiler (1982, p. 15), as pequenas propriedades em 1950 representavam $80,7 \%$, no entanto, ocupavam apenas $20,2 \%$ da área rural. As propriedades com mais de 500 ha, 2,6\%, ocupavam 
$52,0 \%$ de área. As propriedades com mais de 1.000 hectares reuniam 8.766 .451 hectares, apenas nas mãos de 3.586 proprietários, ou seja, quase o dobro da área ocupada dos 4.456 .845 de hectares distribuídos às 231.496 famílias com menos de 50 hectares.

A reduzida área para o pequeno produtor era cada vez mais evidente em razão do esgotamento do solo, da redução do tamanho das propriedades rurais em decorrência das partilhas de herança e também dos baixos preços pagos pelos produtos coloniais. Desse modo, pode-se deduzir que a região Norte do estado presenciou grandes processos de desruralização. É no interior dessa questão dos limites para o pequeno camponês que o esgotamento da fronteira agrícola no norte do Rio Grande do Sul já podia ser observado no final da década de 1940, período de forte intrusão de colonos nas reservas indígenas do estado.

Segundo Rückert, “milhares de famílias de camponeses sem terra, os quais haviam se transformado em marginais, retornam ao campo na condição de assalariados. Uma das mais importantes consequências da expansão da triticultura é o extraordinário encarecimento das terras que ela provocou" (RUCKERT, 1991, p. 75). Com a valorização do arrendamento das terras, ser proprietário de áreas era um ótimo negócio. As aquisições cada vez maiores pelos grandes proprietários, que se modernizavam na produção de cereais, revelavam a tendência da expropriação da pequena propriedade, em consonância das transformações estruturais do capitalismo no Brasil. Segundo Ruckert (2003, p. 165), utilizando-se dos dados dos censos agropecuários do IBGE de 1950 e 1960, a área arrendada na região de Passo Fundo, em 1950 , era de $12 \%$, passando a $16,5 \%$ em 1960. A transformação dos campos de pecuária em terras de negócio por capitalistas arrendatários permitiu a consolidação como fator de negócio, reserva de valor e renda fundiária.

\section{O Master: suas correlações políticas e a reforma agrária - meados do século XX}

O tema da reforma agrária ganhou força no cenário nacional no final da década de 1950. Forças políticas antagônicas pressionavam pela sua efetivação ou seu bloqueio; outros se preocupavam com o modo de fazê-lo. 
Trabalhadores rurais, organizados ainda que incipientemente em torno da Ultab, eram enfáticos em dizer que o Brasil, um país imenso, dispunha de terras fertilíssimas, de climas favoráveis para a cultura dos mais variados produtos agrícolas. ${ }^{5}$

No final de 1950, o norte do Rio Grande do Sul apresentava um quadro fundiário de forte crise. Havia grande pressão pela terra, bem como a redução do potencial de absorção de migrantes em Santa Catarina e Paraná, reduzindo, com isso, o ritmo migratório rio-grandense (GEHLEN, 1983). Desse modo, tensões sociais se acirravam em torno da questão da terra no estado, até porque a oferta de trabalho urbano permanecia reduzida; havia a crise da produção do trigo gerada pelas importações desenfreadas a baixo custo. Foi um período de grandes exigências modernizantes em torno da cultura da soja, as quais não levavam em conta a situação de precariedade dos pequenos produtores, em particular, no centro-norte do estado.

No Rio Grande do Sul, o tema da reforma agrária foi foco de debates. Essa questão preocupava a elite agrária (pecuaristas, latifundiários, comerciantes agrícolas e agroindustriais) desde o início da década de 1960 em razão das Reformas de Base, sendo uma delas a viabilização da reforma agrária. As Ligas Camponesas já vinham também, desde meados da década de 1950, atuando no Nordeste brasileiro e, na década de 1960, já havia se constituído num grande movimento social em praticamente todo o Brasil em prol de transformações na estrutura agrária e nos processos de produção para o pequeno agricultor. No Centro-Sul do país, as Ligas possuíam influência do Partido Comunista (PC), bem como de uma ala progressista da Igreja Católica envolvida nos programas da Ação Católica e de outros grupos políticos de menor expressão.

É nesse contexto que irrompe o Movimento dos Agricultores Sem Terra do Rio Grande do Sul (Master). Movimento capitaneado pelo governador Brizola (1958-1962), pelo Partido Comunista, pelas Ligas Camponesas e sindicatos de trabalhadores rurais (estes em formação no período) que se consolidaram, se institucionalizaram e ganharam visibilidade entre os anos de 1960 e 1964 (HARRES, 2014). Porém, a articulação do referido movimento não foi meramente conjuntural, nem regional; havia sim uma correlação e uns fios que se teciam há alguns anos com as mediações

5 Fragmentos de opiniões de grupos a favor da reforma agrária agregados em torno da União Lavradores dos Trabalhadores Agrícolas Brasileiros (Ultab). Jornal O Nacional, Passo Fundo, p. 4, 9 fev. 1962. 
das Ligas Camponesas e com a Ultab. Essas duas, ainda que com pouca expressão no início da década de 1960, contribuíram para legitimar ações de reivindicação na questão fundiária e nos grandes problemas vividos por peões, assalariados rurais, agregados, arrendatários pequenos camponeses em geral (BODEA, 1992; BANDEIRA, 1979).

Ocupações de terras e organizações sindicais rurais já vinham se constituindo no estado. A proliferação dessas ações e a sua dimensão política expressavam a preocupação de entidades, em especial o PCB e o PTB, com a concentração da propriedade, com o esgotamento da fronteira agrícola, a intensa presença de peões, assalariados, parceiros, pequenos proprietários, assalariados rurais, meeiros, arrendatários, agregados, posseiros, filhos de pequenos agricultores (o censo de 1960 indicou a existência de 297.814 agricultores sem terra no estado). ${ }^{6}$

Vários conflitos eclodiram no país, especialmente no Nordeste, no Norte, sudoeste do Paraná e em Goiás, geralmente em torno de lutas de posseiros contra fazendeiros/latifundiários, contra o Estado por terras devolutas, manifestações de triticultores, cooperativistas e sindicatos patronais e de trabalhadores rurais (MARTINS, 1990). Essa realidade demonstrava certo avanço na organização política do campesinato.

A ação do governador Brizola no Rio Grande do Sul em favor da reforma agrária instigou lideranças locais, a favor ou contra, a se pronunciarem em torno do fato. Visitas de secretários do governo e suas comitivas para analisar possíveis áreas a serem desapropriadas e/ ou canalizadas especialmente para fins de reforma agrária ocasionaram comentários inflamados na imprensa local (ECKERT, 1984). O jornal $O$ Nacional de Passo Fundo estampou dezenas de matérias nesse sentido durante o ano de 1962, período de intensa mobilização social e pressão de movimentos, dentre os quais o Master, pela reforma agrária. A seguir, exemplos de matérias a respeito do que nos referimos, principalmente em torno da realidade do latifúndio e do minifúndio no estado:

Entendo que precisamos deixar de lado as palavras e passar a ação! A afirmação é do Governador Leonel Brizola, na conferência pronunciada a 26 de outubro último no colégio Julio de Castilhos, em Porto Alegre. Esse pensamento, menos por força

6 Cf. jornal Correio do Povo, Porto Alegre, 3 jan. 1962. 
das lideranças partidárias, mas como fruto da crescente pressão das massas urbanas e rurais, começa a tornar-se realidade no Brasil, e no Rio Grande do Sul em particular (Jornal O Nacional, Passo Fundo, out. 1962, p. 4).

A assistência ao pequeno e médio produtor em forma de crédito, escolarização, assistência técnica e médico-hospitalar, garantia de preços mínimos, incentivo ao cooperativismo constituíam necessidades urgentes e inadiáveis, "das quais só discordavam apenas os interessados em perpetuar o atual estado de coisas, ou, o que é incompreensível e lamentável, os que não são capazes de compreender um processo histórico irreversível" ( $O$ Nacional, Passo Fundo, p. 4, out., 1962). A propósito dessa questão das associações, do solidarismo e do preço justo ao produtor agrícola, o papa João XXIII, ${ }^{7}$ em sua encíclica Mater et Magistra, afirmou:

Lembre-se também que no plano agrário, como alias em cada campo da produção, é indispensável que os agricultores se unam em sociedades agrícolas, especialmente se é o próprio trabalho familiar que movimenta a empresa. De qualquer modo é conveniente que os lavradores se sintam solidários uns dos outros e colaborem na fundação de cooperativas e associações profissionais necessárias umas e outras para fazer beneficiar os agricultores dos progressos das ciências e técnicas e defendam os preços dos produtos do trabalho. A isto se acrescendo o fato de que, admitido isto, os agricultores estarão em pé de igualdade com as outras classes de trabalhadores que muitas vezes se reúnem em sociedade. ${ }^{8}$

\footnotetext{
7 Papa João XXIII marcou a renovação na doutrina social da Igreja Católica na década posterior à Segunda Guerra Mundial, período esse marcado por grandes transformações no mundo do trabalho, na esfera política (com intensa presença de partidos de base marxista tendo grande adesão, em particular, na Europa), nas dinâmicas de desenvolvimento e das desigualdades sociais. Ele foi uma grande liderança, com forte simpatia e diálogo com o povo simples; seus escritos, principalmente a Encíclica Mater et Magistra (Mãe e Mestra), discutiam temas sociais, principalmente sobre pobreza, trabalho e trabalhadores, desigualdades econômicas e sociais, subdesenvolvimento, etc. Em razão disso, era taxado pela ala conservadora da Igreja Católica como comunista e/ou de ser demasiadamente radical. Foi o Papa que pensou e convocou o Concílio Vaticano II e abriu grande espaço para temas como liberdade religiosa e ecumenismo. Suas encíclicas eram lidas por grupos sociais que lutavam por igualdade, reforma agrária, sindicalismo no Brasil e na América Latina. Ver sobre isso, Medeiros (1989).

8 Articulistas do jornal O Nacional, Passo Fundo, p. 2, 9 fev. 1962.
} 
Continuam os articulistas dizendo que "tem-se aí que a reforma agrária interessa a todos, no campo e na cidade. Tem-se aí que os movimentos dos agricultores sem terra de Nonoai, Camaquã e quantos venham a surgir, no Rio Grande e no Brasil, são movimentos legítimos, normais, sendo frutos naturais da inadequada estrutura agrária vigente". ${ }^{9}$ Em defesa da reforma agrária, Ruy Ramos, um dos ideólogos do PTB, argumenta:

[...] não têm terra 25 milhões de agricultores brasileiros [...]. Através, então, do Movimento de Agricultores Sem Terra em todo o Brasil, pretendemos mobilizar a opinião pública rural e citadina para obter a reforma agrária por meios bons, se possível, mas obtê-la mesmo por qualquer meio [...]. Esperem cinco anos para ver o que vai acontecer. Criada a mentalidade da reforma agrária, força nenhuma será capaz de impedi-la. ${ }^{10}$

Os defensores entendiam que a reforma agrária ainda que estivesse na ordem do dia no campo político e social só seria concretizada pela pressão política, porém pela via da política e por princípios legais, ao mesmo tempo, eram realistas no sentido de que os camponeses não estavam organizados suficientemente para essa pressão e também não havia tido história ainda de um movimento de lutas em torno da questão. Por meio do Master pretendiase convencer a opinião pública sobre a necessidade da reforma agrária. Ruy Ramos sugeria primeiramente os meios legais, no entanto, se necessário, ações menos pacíficas e ortodoxas seriam colocadas em prática.

Segundo Eckert (1984), o Master se consolidou em 1960 por ocasião de uma tentativa de retomada de uma área de 1.800 ha no interior do município de Encruzilhada do Sul, que há cinquenta anos estava em poder de trezentas famílias de posseiros. O proprietário, após quase quarenta anos sem reclamar a propriedade, começou a exigir dos posseiros cobrança pelo uso da terra, induzindo-os e coagindo-os a comprarem a terra sob pena de serem expulsos. A organização dos posseiros pressionados a comprarem as terras contou com o apoio e mediação do prefeito de Encruzilhada do Sul, 
Milton Serres Rodrigues, junto ao governo do Estado para desapropriar as terras mediante o pagamento de apólices estaduais (LEINDECKER, 1987).

Na metade de 1960 foi formado o primeiro núcleo do Master na cidade de Encruzilhada do Sul, tendo à frente o prefeito Milton Serres Rodrigues, Paulo Schilling, superintendente da fronteira do Sudeste, e Ruy Ramos, deputado federal pelo PTB. A partir desse evento pioneiro, iniciou-se a fundação de associações nos moldes da de Encruzilhada do Sul, tentativas de organizar a entidade em nível estadual, participação em congressos, como o da Ultab, para servir de referência à luta dos camponeses sem terra do Rio Grande do Sul. O movimento se embasa, pelo menos no início da pressão e dos acampamentos, na legislação fundiária do Estado nos artigos 173 e 174, que determinam:

O Estado combaterá a propriedade improdutiva, por meio de tributação especial ou mediante desapropriação. Atendendo aos interesses sociais. O Estado poderá, mediante desapropriação, promover justa distribuição da propriedade, de maneira que o maior número possível de familiares venha a ter parte em terras e meios de produção. O Estado promoverá planos especiais de colonização, visando às finalidades do parágrafo anterior, sempre que a medida for pleiteada por um mínimo de cem agricultores sem terras, de determinada região. ${ }^{11}$

No início do movimento, as concepções políticas e as ações estratégicas em torno da questão agrária não estavam muito claras; concepções variadas foram a tônica do movimento, em grande parte em razão dos diversos grupos que o compunham. A legislação servia como uma arma de pressão na esfera pública; os acampamentos na beira da estrada próximos à área pretendida (não caracterizando invasão da propriedade) era uma estratégia de a Justiça não poder removê-los do local. No início buscouse uma solução política e jurídica para apenas uma parte das áreas em litígio (ECKERT, 1984). A Fazenda Sarandi e o Banhado do Colégio em Camaquã (este repercutiu por ser uma imensa extensão de terra pública - em torno 
de 50.000 ha - na qual o Estado estava fazendo grandes investimentos em obras de saneamento e de irrigação) foram os mais expressivos pela forte vinculação com o governador Brizola (ECKERT, 1984).

É importante ressaltar que o Master foi, no seu nascedouro, um movimento institucionalizado de cima para baixo por alguns proprietários rurais e intelectuais das fileiras do PTB, sensíveis à questão agrária no estado, principalmente em torno da pressão e da organização, embora incipiente, de um contingente imenso de pequenos agricultores, arrendatários, assalariados rurais, dentre outros.

O manifesto de Encruzilhada do Sul como expressão do nascedouro do Master continha alguns aspectos que, posteriormente, seriam o suporte político e ideológico do movimento. Dentre esses aspectos, o problema do monopólio da terra e a utilidade produtiva para quem nela trabalhasse (esse aspecto estava em consonância com a pregação da Igreja Católica do momento), a pressão política das massas rurais para a realização da reforma agrária, necessidade de tornar os pequenos produtores sujeitos do processo de reivindicação junto aos poderes políticos constituídos (embora essa meta tenha, de certa forma, fracassado pela forma pouco democrática como eram feitos os encaminhamentos e a direção centralizada), questões em torno dos custos dos insumos, questões relacionadas à orientação técnica, do baixo preço dos produtos, preços mínimos, redução de importação de trigo etc.

A questão da reforma agrária apareceu como secundária na pauta de reivindicações do movimento nascente. Falava-se em desapropriação do latifúndio antieconômico, de áreas improdutivas, núcleos coloniais para camponeses sem terra, melhores preços agrícolas, redução dos custos dos insumos, redução das importações de trigo, educação rural etc. Também pouco ou nada se falava sobre a situação dos assalariados rurais (ou seja, da extensão da CLT para as atividades agrícolas). As adesões de agricultores e as mediações políticas foram variadas; conflitos internos não eram incomuns, mesmo quando sob a orientação ideológica e política do PTB, em especial, de Brizola.

Brizola no início de seu governo, segundo Eckert (1984), não tinha assumido a questão da reforma agrária como prioridade, não obstante reconhecesse o êxodo rural, a concentração da propriedade, a necessidade de reforma agrária, a existência de um contingente de expropriados rurais pelo latifúndio e pelas políticas agrícolas de então. 
Eckert enfatiza que nessa fase de organização do movimento a presença do governador tinha por objetivo angariar simpatia popular (tendo em vista as eleições de 1962), estender as bases de pressão para a aprovação das reformas de base, fomentar ideias anti-imperialistas e desenvolver a industrialização no país. Em 1961, numa postura voluntarista e populista, colocou à disposição para a reforma agrária suas terras na Fazenda Pangaré, em Osório. Instituiu grupos para viabilizar a instalação de colônias agrícolas e programas especiais para a reforma agrária e o desenvolvimento econômico do meio rural (ECKERT, 1984).

Os vínculos entre PCB, o Master e o Governador Brizola advêm do apoio político que esse recebeu daquele partido por ocasião das eleições de 1958, além do que, fazia parte da postura política do PCB se aliar às forças interessadas na luta contra o imperialismo e o latifúndio, luta também apoiada por setores do trabalhismo interessados em ampliar o seu respaldo junto aos setores populares do campo (ECKERT, 1984).

O Master foi verdadeiramente reconhecido pelas forças políticas e demonstrou seu poder de organização e ação por ocasião do primeiro congresso de 15 a 17 de dezembro de 1962. No evento estiveram presentes representantes do governo estadual, sindicatos urbanos estaduais, delegados de outros estados e um representante da Ultab. Nessa ocasião, foram redefinidas as ações, os rumos e a radicalização da luta pela reforma agrária, assim como revelar os grupos que lutavam pela hegemonia interna e explicitar as várias concepções em torno das questões marcantes do problema fundiário no estado e no país (ZANFELIZ, 1980, p. 63).

As metas eram difundir a pequena e média propriedade, democratizar o acesso à terra, levar os ventos da modernidade ao campesinato, facilitar formas de organização em cooperativas e associativas, sem necessitar de enfrentar diretamente o problema da concentração fundiária, e bater de frente com entidades representativas do latifúndio que o sustentaram politicamente no estado. 


\section{O acampamento Capão da Cascavel: a reforma agrária na} pauta no movimento

No início da década de 1960, no município de Sarandi, a atenção dos movimentos se voltara para a Fazenda Sarandi, onde se localizava uma área remanescente de uma antiga posse de mais de 70.000 ha. Constituíase de um latifúndio de mais de 21.000 ha de terra, sendo propriedade de uma família de uruguaios (sobrenome Mailhos), que morava em Montevidéu (RUCKERT, 2003). A área era arrendada para agricultores e pecuaristas.

$\mathrm{O}$ acampamento foi instalado na beira da estrada para que não tomassem como justificativa a invasão de propriedade. Começou com trezentas pessoas, e em poucos dias contabilizava mais de 1.300 pessoas. A mobilização dos sem terra, mediados por líderes do PTB, na intensa demanda pela terra, impactou todos os setores da comunidade gaúcha. Quase a totalidade reconhecia o problema e apelava pela solução na esfera pública. Daí em diante, o acampamento somava mais e mais adeptos, chegando à cifra de dez mil pessoas em meados de 1962 (ECKERT, 1984).

O acampamento de Capão da Cascavel esteve sob o olhar vigilante e muito bem informado nos mínimos detalhes do governador Brizola, para dar continuidade às desapropriações, dessa vez na Fazenda Sarandi. Antes disso tinha de se criar um fato social de grande repercussão para justificar a desapropriação. O governador chamou ao palácio Piratini seu primo-irmão Jair de Moura Calixto, prefeito de Nonoai, para organizar o movimento. Calixto era uma liderança de grande prestígio na região, apesar de ter também muitos desafetos. Homem de total confiança de Brizola, Calixto havia dado provas de sua liderança política e capital social junto aos pequenos agricultores do seu município e parte do norte do estado. Foi também corajoso e destemido durante a campanha da Legalidade em agosto de 1961. Na organização do movimento na região de sua ação política, Calixto contou com a colaboração de vários líderes (HARRES, 2014).

A organização do acampamento de Capão da Cascavel foi planejada ainda em Nonoai pelo prefeito Calixto. O município passou a ser o ponto de articulação e a principal base de apoio ao movimento. Os agricultores foram mobilizados e recrutados num curto espaço de tempo pelas lideranças regionais, capitaneadas pelo prefeito, que mandou emissários em todas as casas. Porém, nem todas as lideranças regionais no início do movimento estavam em sintonia, conforme algumas matérias publicadas na imprensa. Um jornal da capital gaúcha, em matéria de capa, informava: 


\begin{abstract}
Denuncia o prefeito de Sarandi: Mil homens de Nonoai se aprestam para invadir terras de Sarandi. Como tivemos oportunidade de informar, esboça-se no município de Nonoai um movimento visando à entrega de terras a agricultores, com o beneplácito, senão a liderança, do prefeito Jair Calixto. Pois em encontro que ontem mantivemos com o prefeito de Sarandi, sr. Ivo Sprandel [...], fomos surpreendidos com a manifestação de S. S.a de que Nonoai quer fazer reforma agrária à custa do município de Sarandi. Convidado a entrar em detalhes acerca da curiosa situação, disse-nos o senhor Ivo Sprandel: - Em verdade, sábado último, fui procurado por uma comissão de pecuaristas e agricultores arrendatários de terras da Fazenda Sarandi, de propriedade da firma Estância Júlio Maílhos, com sede em Montevidéu, que veio manifestar seu temor com referência a esses rumores oriundos de Sarandi. Uma medida dessa ordem, que contraria frontalmente os dispositivos constitucionais. ${ }^{12}$
\end{abstract}

De acordo com a matéria divulgada, o prefeito de Sarandi parecia estar numa situação difícil de escolher: ou ficar do lado dos agricultores e pecuaristas arrendatários da Fazenda Sarandi ou ficar do lado dos sem terra. Todavia, percebendo o sucesso do movimento, aderiu ao grupo de Calixto, e passou a apoiá-lo como se estivesse integrado aos princípios ideológicos. Segundo Gehlen (1983), Sprandel decidiu apoiar a invasão por pressão do governador.

Brizola orientou Calixto a organizar a ocupação da área de Capão da Cascavel, ignorando os apelos do prefeito de Sarandi de ocupar a Fazenda Annoni, que pertencia a Ernesto José Annoni, então prefeito de Carazinho pelo PTB e correligionário do governador. Havia também uma disputa entre Sprandel e Calixto pela liderança política em nível regional, isto é, ambos disputavam o mesmo reduto eleitoral do PTB.

De acordo com algumas matérias publicadas nos jornais, o governador Brizola procurou mostrar para a opinião pública que o ato partira exclusivamente da iniciativa de Calixto e de seus asseclas, ainda que o governo estivesse de acordo com "um movimento pacífico". É o que se depreende pela matéria:

12 Jornal Correio do Povo, Porto Alegre, p. 16, 12 jan. 1962. 
Informa-se, outrossim, que em face da comunicação feita pelo prefeito Ivo Sprandel às autoridades estaduais, o governador Leonel Brizola teria mandado chamar a esta Capital o prefeito de Nonoai, sr. Jair Calixto, a fim de inteirar-se da situação reinante em seu município e, se fosse o caso, para "moderar os ímpetos reformistas" de S.S.a do qual, como se sabe, o chefe do Executivo é parente próximo. ${ }^{13}$

As preocupações de Brizola com a ordem pública, com a possibilidade de ideologização do movimento ou a ideia de que o movimento parecesse comunista, revolucionário, ou subversivo eram constantes:

Isto não é invasão, Calixto. Que ninguém meta o pé além do alambrado! Quero que respeitem as propriedades particulares. Cuida para não entrar no grupo algum agitador. O que nós precisamos é criar um clima social pacífico, para facilitar a desapropriação (BRIZOLA, apud CASALI, 2005, p. 141).

Jornais registram que Brizola orientava determinadas invasões em várias partes do estado e determinava que fossem plantadas cruzes no centro do acampamento "para que mais tarde não nos chamassem de comunistas". ${ }^{14}$ Estratégias para criar um "clima social pacífico", segundo os entrevistados, era conquistar o apoio da Igreja Católica, bastante reticente, e em certos momentos mais abertamente contrária ao movimento, confirmando sua oposição em relação ao Master. 


\section{"Quem tem terra tá com Cristo, quem não tem tá com Calixto". ${ }^{15}$ A Igreja Católica e o Master}

No início da década de 1960, a postura da Igreja Católica no Brasil estava distante das influências das teses do Concílio Vaticano II e das decisões da Conferência de Medellín (Colômbia, 1968). ${ }^{16}$ No Rio Grande do Sul, estava concentrada nas diretrizes do arcebispo de Porto Alegre, dom Vicente Scherer. Arcebispo desde 1947, mantinha a maior parte do clero subordinado às suas ordens e fiel às suas teses, sendo sua principal obsessão o "anticomunismo". Segundo Hammes (2003, p. 76), "Dom Vicente, como fiel escudeiro do papa Pio XII, introjetara que o comunismo era tudo o que não prestava. Por isso, cismava em combater tudo aquilo que pudesse ter alguma semelhança com a doutrina marxista ou que pudesse caracterizar alguma aproximação com países comunistas." Na mensagem de abertura do ano litúrgico de 1962, Scherer manifestou-se nos seguintes termos:

Os vanguardeiros das forças de Moscou agem com disfarces, aliciando adeptos e ocupando posições [...]. Não promovemos campanhas negativas de anticomunismo, mostramos os erros da ideologia marxista pelo debate dos princípios doutrinários em que se funda e pelo exame da experiência desastrosa que se está fazendo nos países já dominados pelas forças aguerridas do novo império colonialista. ${ }^{17}$

Por ordem de Brizola, um padre devia ir ao acampamento rezar missa. Ele recomendou a Calixto para que fosse erguida uma cruz no acampamento e afixadas faixas dando ênfase ao aspecto religioso. Casali, em seu diário, registrou a visita que fez ao acampamento no dia 13 de janeiro de 1962, sábado, dizendo ter encontrado "em frente à faixa que liga Ronda Alta a Passo Fundo, uma capelinha de madeira abrigando a imagem da Santa Terezinha. Atrás dela, a cruz de madeira erguida à semelhança daquela de Cabral. Encimando a cruz, um cartaz em pano branco, com escrita preta: 'Somos cristãos! Queremos terra'" (CASALI, 2005, p. 146).

Com o propósito de dar ainda mais ênfase ao caráter religioso, o acampamento foi batizado com o nome do papa João XXIII. Logo na entrada 
foi identificado por uma faixa: “Acampamento João XXIII” (CASALI, 2005). Porém, só isso não bastava. Era necessária a presença do padre para rezar a missa, dar a bênção aos barracos. Assim, em 14 de janeiro, domingo, o padre de Sarandi esteve no acampamento para rezar a missa aos acampados. Havia uma constante preocupação de mostrar nas aparências e ações práticas que o movimento era cristão e, por isso, anticomunista. Dessa forma, Brizola atendia aos interesses de uma ala da Igreja e não agredia em demasia a outra; buscava, dessa maneira, adeptos influenciados pela sua política em torno do que considerava reforma agrária.

Por ocasião da presença do governador e do seu discurso no acampamento, citações da Mater et Magistra foram pronunciadas, dentre as quais as que enfatizavam o direito à propriedade particular "desde que seu uso corresponda aos interesses coletivos" (GEHLEN, 1983, p. 86).

A correlação entre o "ser cristão" e o "não ser comunista" dava ao movimento um caráter de movimento "ordeiro", "pacífico" e limitado à reivindicação de um pedaço de terra. O registro encontrado na obra de Casali sobre o discurso de Brizola, em visita ao acampamento em 15 de janeiro de 1962, é elucidativo nesse aspecto:

Aí Brizola perguntou: "Quem é cristão, levante o braço!” [...]. Todo mundo explodiu num delírio, levantando os braços. Enquanto isso, um gritou: "Taí o padre que rezou a missa com nós ontem, aqui na capelinha! "E agora, quem for comunista que erga a mão!” Silêncio total. E novo delírio! (CASALI, 2005, p. 151).

A Igreja Católica, apesar de aparentemente se manter distante do movimento em termos de mediação/doutrinação ou conscientização, acabou emprestando sua ajuda de forma indireta, contribuindo na consolidação de um projeto de movimento social organizado em torno de fortes lideranças carismáticas e/ou paternalistas. Os ideólogos da Frente Agrária Gaúcha (FAG), dentre os quais D. Edmundo Kunz, reconheciam os humildes e indefesos lavradores do campo, porém, como a questão da terra estava em evidência no contexto nacional, era importante livrá-los dos "lobos marxistas e dos agitadores do Master", apresentando uma alternativa dentro do "contexto cristão". A Igreja Católica, através dos quadros da FAG, reconhecia a concentração da terra, porém não agia no sentido de alterar esse 
processo. (WARREN, 2005).

Figura 1 - Governador Brizola em meio aos acampados do Capão da Cascavel, em 15 de janeiro de 1962. Ele esteve presente na distribuição dos lotes aos agricultores.

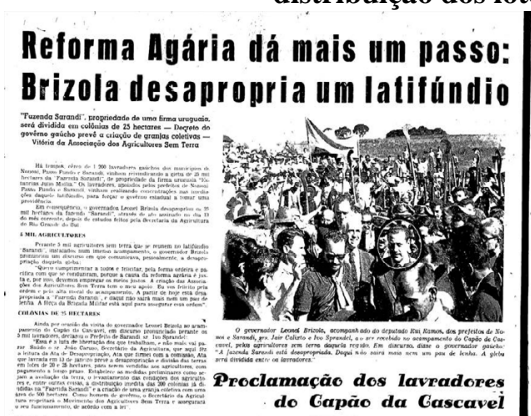

Mais um assalto das máquinas americanas aos plantadores
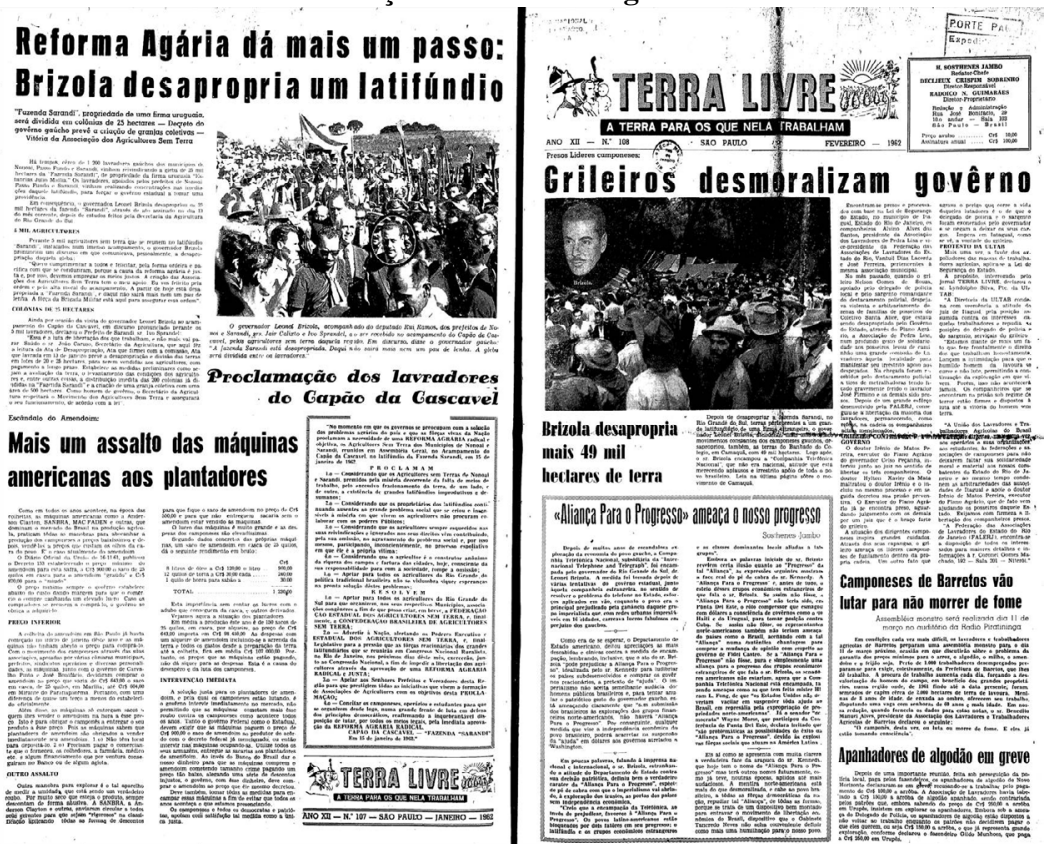

Fonte: Jornal Terra Livre, São Paulo, p. 2, 1962.

Adesapropriação e a distribuição de títulos aos agricultores

O desfecho do movimento de Capão da Cascavel deu-se com a desapropriação de uma área de $21.889,14$ ha através do decreto estadual $\mathrm{n}^{\circ} 13.034$ de 13 de janeiro de 1962, abrangendo a Agropecuária Lucena S. 
A., com 6.151,28 ha; a Ganadero Horácio Mailhos, com 7.087,86 ha, e a Estância Júlio Mailhos, com 8.650,00 ha (CASALI, 2005, p. 155).

Encerra-se o caso dos sem terra em Nonoai

O Governador Brizola assinou, sábado o Decreto 13.034 declarando de utilidade pública para fins de desapropriação por interesse social, as três fazendas do Sarandi. A área a ser desapropriada eleva-se a 24.239 hectares de terras e matos. Acentua o documento que o movimento dos "agricultores sem terra", que motivou o ato do governo, não se afastou da ordem, conservando sempre o caráter pacífico [...]. ${ }^{18}$

No discurso, Brizola comunicou a desapropriação da Fazenda Sarandi nesses termos:

[...] quero cumprimentar a todos e felicitar, pela forma ordeira e pacífica com que se conduziram, por que a causa da reforma agrária é justa, e por isso, devemos empregar os meios justos. A criação das Associações de Sem Terra tem o meu apoio. Eu vos felicito pela ordem e pela alta moral do acampamento. A partir de hoje está desapropriada a Fazenda Sarandi e daqui não sairá mais um pau de lenha. A força da Brigada Militar está aqui para assegurar essa ordem. ${ }^{19}$

O plano de colonização da área desapropriada foi elaborado pelo Instituto Gaúcho de Reforma Agrária (Igra), órgão do Estado. Foi apresentado aos sem terra no acampamento durante a ocupação. A lista dos futuros beneficiários dos lotes foi elaborada pelas lideranças do movimento com a assessoria de pessoas ligadas ao Igra e à Diretoria Estadual de Terras Públicas de Nonoai. Havia regras para o recebimento dos lotes, como, por 
exemplo, cada sem terra inscrito receberia determinada pontuação se tinha condições de ser apto para a atividade agrícola. Em outras palavras, o sem terra precisava ter arado, carroça, enxada, animais domesticados para o uso na lavoura etc. Ocorreu também que muitos iam acampar de carroça levando o que tinham de ferramentas para o serviço da lavoura, se, porventura, não dispusesse dessas ferramentas, a própria carroça e os bois eram um indicativo.

No mesmo dia da desapropriação, representantes dos colonos e dos mediadores, a maioria do PTB, reuniram-se para lançar um manifesto intitulado "Proclamação dos Lavradores do Capão de Cascavel". Percebe-se nesse manifesto a organização dos agricultores do Rio Grande do Sul para conseguir, em nível estadual e nacional, o necessário apoio das entidades regionais, a agregação de operários e estudantes e todos os interessados em lutar por meios legais pela aprovação da reforma agrária, dentre outras questões. No manifesto, ficaram evidentes as influências dos mediadores, misturando intenções, mesmo assim todas convergindo para o problema fundiário do estado e a democratização do acesso à terra pelos camponeses (ECKERT, 1984).

O critério utilizado na distribuição da terra na Fazenda Sarandi, a partir de certas condições dos agricultores, caminhava ao encontro da visão do PTB sobre a reforma agrária. O PTB rio-grandense era herdeiro das ideias do líder trabalhista brasileiro Alberto Pasqualini. ${ }^{20}$ Segundo ele, a "reforma agrária não significa apenas distribuição da terra. A terra pouco adianta sem meios técnicos e recursos para cultivá-la" (GEHLEN, 1983, p. 90).

A dimensão progressista, modernista e estatista da questão fundiária estava presente constantemente nos discursos de Brizola, também nas manifestações de apoio dos intelectuais e granjeiros do PTB gaúcho. Os pequenos arrendatários que estavam já na Fazenda Sarandi, inicialmente eram contrários à ocupação pelos sem terra, mas aos poucos foram sendo cooptados pelo movimento e muitos acabaram beneficiados com lotes que variavam de 10 a 20 ha. Os grandes arrendatários também foram beneficiados com a distribuição de 16 lotes com maior quantidade de terra, podendo chegar até 50 ha. Esse ato se revestiu de certo simbolismo,

20 Político brasileiro, nasceu no Rio Grande do Sul (1901) e morreu no Rio de Janeiro (1960). Defendeu no Brasil uma ação trabalhista semelhante à do Partido Trabalhista da Inglaterra. Participou da Revolução de 1930, foi vereador em Porto Alegre (1934), secretário do Interior e da Justiça do Rio Grande do Sul (1944) e senador por este estado (1950). 
pois serviu para apagar o estigma de que a reforma agrária pretendida por Brizola tinha um caráter revolucionário. Há que se entender ainda o fato de que em Carazinho, forte reduto do brizolismo, os ruralistas tinham expressiva presença nas fileiras do PTB.

Havia divisões entre os sem terra que ocuparam a Fazenda Sarandi no movimento de Capão da Cascavel. Basicamente havia três grupos: os que não possuíam terra e recursos para a atividade agrícola; os que não tinham terra, animais e equipamentos próprios para a agricultura familiar; e os granjeiros mecanizados, antes arrendatários da fazenda. Os únicos alijados do processo de assentamento foram os primeiros, justamente os mais necessitados.

\section{Distribuição de terra e capital político}

Em janeiro de 1962, o governador Brizola desapropriou a fazenda depositando 63 milhões de cruzeiros nas contas dos proprietários uruguaios. Assim, viabilizava uma primeira estratégia de colonização, dividindo a área de 17.000 ha em 450 lotes coloniais aos agricultores que possuíssem algum tipo de maquinário ou instrumentos para o trabalho agrícola. Os 5.000 ha restantes foram divididos nas glebas Brilhante, com 1.450 ha, e Macali, com 1.600 ha, e que vinham sendo arrendadas pelos uruguaios Mailhos S.A. para o cultivo de trigo dos capitalistas de Passo Fundo e Carazinho desde a década de 1950; uma gleba para a administração do projeto, conhecida por área da Cemapa, órgão da Secretaria da Agricultura do Estado; e uma reserva florestal no município de Rondinha (RUCKERT; DAL MORO, 1986).

Se não bastasse o expressivo número de camponeses alijados do processo de assentamento, a distribuição dos lotes aos contemplados iniciada no governo de Brizola, prosseguiu lentamente no governo de Meneghetti, do PSD (de oposição a Brizola, que foi eleito e assumiu o poder do estado em 1963). Desse modo, o movimento de Capão da Cascavel não teve como resultado final a efetiva conquista de toda a área da Fazenda Sarandi e também a solução do problema da falta de terra para centenas de camponeses pobres.

Vários desdobramentos resultaram desse problema não resolvido por inteiro. Além das investidas na Fazenda Sarandi, intensificaram-se as 
tentativas de ocupação das reservas indígenas e das reservas florestais. A repercussão maior ocorreu no início de 1963 no governo de Meneghetti, quando da ocupação da reserva florestal de Nonoai, anexa à reserva indígena denominada Passo Feio. Os agricultores que não haviam sido contemplados na Fazenda Sarandi dirigiram-se para essa área. Muitos outros conflitos semelhantes ocorreram a partir do final da década de 1970.

É importante frisar que desde a origem do evento de Capão da Cascavel constituiu-se um plano articulado com a participação do governador Brizola, na concepção paternalista e primando sempre pela manutenção da ordem. A análise das fontes de pesquisa dá a entender que a terra foi distribuída muito mais como um "gesto de benevolência" do governo Brizola do que resultado de uma ação coletiva, ainda que tenha havido organização e mobilização do grupo. Os registros de Casali sobre a chegada de Brizola ao acampamento, em 15 de janeiro de 1962, são emblemáticos nesse sentido:

Os acampados estão se organizando para receber o Governador e alguns já vestem suas roupas domingueiras [...]. Nesta altura são 16 horas e mais de 10.000 pessoas se acotovelam diante das barrancas da Fazenda Sarandi. De repente os alto-falantes anunciam que dois aviões surgem no horizonte, se aproximam e sobrevoam o acampamento... Delírio geral! Chegou o nosso líder! Diziam os colonos. "Muito bem, cabocla velha, você é um exemplo de mulher. Vou recomendar para você que lhe seja destinado 25 ha de terra. Vai ter terra para toda a família. Ensina os meninos a cultivá-la com carinho e técnica”. E, abraçando a dona Emília, acariciou uma vez as crianças, que lhe diziam: "Viva o Brizola" (CASALI, 2005, p. 150).

O caráter populista se expressa nas várias manchetes de jornais da região. Como um "Messias", Brizola chegou ao acampamento para tirar os colonos das trevas. O povo aguardava de mãos estendidas. A concessão da terra era reconhecida como um favor e não como um direito ou resultado de uma mobilização e luta dos camponeses. Alguns meios de comunicação ressaltavam o ineditismo da ação de Brizola no caso da Fazenda Sarandi, aludindo que se tratava de um marco para a história agrária no Rio Grande do Sul, conforme é possível deduzir da matéria de capa do jornal Oeste Catarinense: 
Implantada a reforma agrária no Rio Grande do Sul, através do seu Governador Leonel Brizola, acaba de iniciar movimento instituindo a reforma agrária. O flagrante foi colhido em Capão da Cascavel, quando o Governador gaúcho atendia às reivindicações dos agricultores sem terra. ${ }^{21}$

O acampamento na Fazenda Sarandi passou a ser referenciado no interior do movimento e da imprensa local pela sua expressão e manifestação da popularidade do governador que esteve pessoalmente no local. Fez um discurso extremamente populista em torno do tema das reformas de base contra o latifúndio, contra o imperialismo (se referindo aos proprietários da gleba que eram estrangeiros), etc. Porém, enfatiza-se que nem todos os acampamentos do Master tiveram tanto apoio e um princípio de resolução no governo Brizola como este em questão.

Brizola, ao mesmo tempo em que apoiava as ações do movimento, acordava com a Farsul (órgão de representação dos interesses do grande capital fundiário no estado), além de levar em conta as garantias do direito à propriedade, uma reforma agrária "na lei", "no bem" e "na ordem", sem violência, sem desapropriações indevidas, ainda que reconhecesse a necessidade de atender uma "justa reivindicação social" dos agricultores. Para garantir essa ação caracterizada pela ambiguidade, Brizola acionou terras públicas, reservas indígenas (reduzindo-as e/ou extinguindo-as), pensando, inclusive, desapropriar terras na beira das rodovias, rios e açudes. Como gesto de benevolência para com a reforma agrária, num determinado momento resolveu desapropriar parte da Fazenda Pangaré, situada no município de Osório, de propriedade da família Goulart, que pertencia à esposa Neusa Goulart e ao cunhado ex-presidente João Goulart.

O movimento de Capão da Cascavel na Fazenda Sarandi se manifestou muito mais como um movimento estratégico, organizado pelo governador Leonel de Moura Brizola, contando com a participação de lideranças políticas locais (como Calixto), com finalidades previsíveis, do que propriamente um movimento social de base popular e ideologia campesina. Ainda que os interesses dos camponeses girassem em torno da luta pela terra, a participação de Brizola foi muito mais uma tentativa de 
reação, de autoafirmação e sobrevivência do nacional-populismo em crise desde meados de 1961 com a ascensão de Jango à Presidência da República, cujo desfecho resultou na deflagração da campanha da Legalidade no Rio Grande do Sul.

A quantidade de interessados pela terra da fazenda desapropriada não permitia assentar todos os camponeses pretendentes a um pedaço de chão. Houve pressão popular nesse sentido, organizada pelo prefeito Calixto. Para atender as demandas em várias regiões do estado, o governador extinguiu algumas reservas indígenas, expulsando e obrigando os indígenas a se inserirem em outras reservas. No norte do estado, as reservas de Serrinha (em Engenho Velho), de Ventarra (em Erebango) e de Monte Caseiros (em Lagoa Vermelha, atual Caseiros) foram completamente extintas. Outras sofreram redução significativa da área com a permissão da entrada e aquisição de terras por camponeses.

O processo de reestruturação fundiária pela esfera pública produziu consequências nos atuais movimentos sociais na luta pela terra no estado, em particular na parte norte entre indígenas e agricultores. Atualmente, essa região possui mais de duas dezenas de acampamentos indígenas com processos administrativos em andamento reivindicando as áreas originais que foram suprimidas de seus aldeamentos, assim como o retorno às reservas extintas. Esse processo vem produzindo novos conflitos e tensões sociais, embates jurídicos, mediações políticas e tomadas de posição de entidades sociais.

\section{Considerações finais}

As ações do Governador Brizola junto ao Master, em particular, no Capão da Cascavel, preocupavam aqueles que viam a reforma agrária ou o comunismo como uma ameaça social e política. A desapropriação da terra para a reforma agrária representava para Brizola o coroamento de um projeto ambicioso. Em primeiro lugar, a reforma agrária atendia a principal meta das reformas de base e uma das grandes bandeiras do trabalhismo; em segundo lugar, a desapropriação de terras de estrangeiros representava uma atitude nacionalista, vista com simpatia pela elite agrária ligada ao PTB. Assim, acabou contentando os dois lados: os sem terra e os médios e grandes 
proprietários nacionais.

Por isso, no tocante aos conflitos da Fazenda Sarandi, a oposição ao movimento não foi tão forte da parte dos latifundiários congregados à Farsul, dentre outras entidades que se opuseram com firmeza quando da invasão de inúmeras outras glebas produtivas e/ou improdutivas. A Fazenda Sarandi apareceu a Brizola e às forças expressivas do latifúndio como emblemática para a solução agrária.

Apesar de limitada, a oposição ao movimento pela desapropriação da Fazenda Sarandi fez-se presente em vários momentos. Alguns deputados da oposição ao governo Brizola vociferavam na tribuna do Parlamento gaúcho contra a decisão do governador ao desapropriar uma área onde havia "extensas áreas cobertas de matas reflorestadas, campos arrendados, povoados com gado e grandes plantações de soja, milho e trigo, além da existência de pelo menos uma serraria". ${ }^{22}$

O movimento de Capão da Cascavel deve ser considerado emblemático tanto no contexto das análises de iniciativas, propostas, lideranças e desdobramentos, que culminaram com a formação do Master no norte do Rio Grande do Sul, quanto no plano das ações práticas dirigidas à efetivação de uma iniciativa de projeto de reforma agrária pelo Estado. Muitos desdobramentos posteriores ligados à questão da terra foram espelhados no evento de Capão da Cascavel, e se tornaram possíveis por causa dele.

No bojo das intenções do governador Brizola, as reservas indígenas foram vistas como as últimas esperanças dos sem terra ante a falta de um projeto de reforma agrária mais ampla e que atingisse a histórica estrutura latifundiária. O Estado, pressionado pelas forças representativas do grande capital e do latifúndio, não titubeou diante de tal contexto: extinguiu as reservas e retalhou outras áreas, como a de Nonoai. Uma das iniciativas do Estado gaúcho que acabou acelerando o esbulho das terras indígenas foi a criação das reservas florestais, subtraindo as terras dos indígenas. Decididamente, esse foi o primeiro golpe desterritorializador dos kaingang. A criação de reservas florestais foi uma clara afronta à legislação federal, já que as terras dos índios são da União. ${ }^{23} \mathrm{O}$ Estado gaúcho não podia legislar

22 Jornal Correio do Povo Rural, Porto Alegre, 19 jan. 1962.

23 A criação das reservas florestais, em 1941, por ato do interventor federal no estado, Cordeiro de Farias, por mais paradoxal que possa parecer, acelerou o desmatamento. A terra sem índios, passou a ser invadida com mais facilidade, sendo incorporada às paisagens agrícolas circundantes. 
sobre essa matéria, porque a questão era da alçada da esfera federal.

O movimento Master seguiu as demandas e estratégias da luta pela terra até o início do golpe civil-militar, em várias partes do estado. Porém, com a saída de Brizola do governo, outros grupos tornaram-se centrais no comando do movimento, entre os quais o PCB, que redefiniu as estratégias e bandeiras, e a reforma agrária ficou mais radicalizada. Com isso surgiram contraposições mais efetivas de entidades em defesa do latifúndio e divisões no interior do movimento. No golpe militar, vários líderes do Master foram presos, outros exilados, alguns serviram de delatores, resultando na extinção do movimento. No entanto, da mesma forma que suas demandas produziram conflitos no meio indígena em razão das ações do governo, a experiência de luta do Master embasou a luta pela terra no início de 1980 em várias partes do país, com destaque para o norte do Rio Grande do Sul, através da presença de lideranças já experientes, com estratégias e convicções de que a estrutura fundiária do país só poderia ser alterada pela pressão dos grupos sociais organizados.

\section{Referências bibliográficas}

BANDEIRA, L. A, M. 1979. Brizola e o trabalhismo. Rio de Janeiro: Civilização Brasileira.

BANDEIRA, M. 1979. Brizola e o trabalhismo. Rio de Janeiro: Civilização Brasileira.

BODEA, M. 1992. Trabalhismo e populismo no Rio Grande do Sul. Porto Alegre: Ed. da Universidade.

BRUM, A. 1997. O desenvolvimento econômico brasileiro. 17. ed. Petrópolis: Vozes; Ijuí: Editora Unijuí.

CARINI, J. J. 2005. Estados, índios e colonos: o conflito na reserva indígena de Serrinha - norte do Rio Grande do Sul. Passo Fundo: UPF Editora.

CARONE, E. 1982. O PCB (1943-64). São Paulo: Difel. v. 2.

CASALI, J. A. 2005. Memórias de Brizola - o guerreiro do povo brasileiro. 
Erechim/RS: Gráfica São Cristóvão.

CUNHA, P. R. da (Org.). 2004. O camponês e a história: a construção da Ultab e a formação da Contag nas memórias de Lyndolpho Silva. São Paulo: Ipso.

ECKERT, C. 1984. Movimento dos Agricultores Sem Terra no Rio Grande do Sul: 1960-1964. Rio de Janeiro: UFRRJ. Dissertação em Desenvolvimento e Agricultura.

GEHLEN, I. 1983. Uma estratégia camponesa de conquista da terra e o Estado: o caso da fazenda Sarandi. Porto Alegre: UFRGS. Dissertação em Sociologia.

GREGORY, V. 2002. Os eurobrasileiros e o espaço colonial: migrações no oeste do Paraná - 1940-1970.

HAMMES, R. 2003. Igreja Católica, sindicatos e movimentos sociais: quarenta anos de história, projetando luzes para a defesa e a promoção da vida na região. Santa Cruz do Sul/RS: Edunisc.

HARRES, M. M. 2014. Estratégias trabalhistas para o mundo rural: governo Leonel Brizola no Rio Grande do Sul. São Leopoldo: Oikos.

LEINDECKER, D. T. 1987. Uma experiência de reforma agrária: Banhada do Colégio, no município de Camaquã, 1962. Revista História, Porto Alegre, n. 1, p. 55-76.

MARTINS, J. de S. 1990. Os camponeses e a política no Brasil. Petrópolis: Vozes.

MEDEIROS, L. S. 1989. História dos movimentos sociais no campo. Rio de Janeiro: Fase.

OHLWEILER, O. A. 1982. Sobre o processo do desenvolvimento econômico do Rio Grande do Sul. Ensaios FEE, Porto Alegre, v. 3, n. 2, p. 5-40.

PESAVENTO, S. J. 1982. História do Rio Grande do Sul. Porto Alegre: Mercado Aberto.

RICCI, R. 1999. Terra de ninguém: representação sindical rural no Brasil. Campinas: Unicamp.

RÜCKERT, A. 1991. A produção capitalista do espaço: construção, destruição e reconstrução do território rio-grandense. Rio Claro: Unesp. Dissertação em Geografia. 
RÜCKERT, A. A. 2003. Metamorfoses do território: a agricultura de trigo/ soja no Planalto Médio rio-grandense, 1930-1990. Porto Alegre: Editora da UFRGS.

RÜCKERT, A.; DAL MORO, S. M. 1986. A agricultura no processo de desenvolvimento no Planalto rio-grandense. Revista de Filosofia e Ciências Humanas, Passo Fundo: UPF, ano 1, n. 3, p. 43-67.

WARREN, I. S. 2005. Redes de movimentos sociais. 3. ed. São Paulo: Loyola.

Zanfeliz, M. A. 1980. As relações sócio-políticas no Rio Grande do Sul: governo, partidos e sindicatos na conjuntura de 1958-1964. Porto Alegre: Editora da UFRGS.

ZARTH, P. 2002. Do arcaico ao moderno: o Rio Grande do Sul agrário do século XIX. Ijuí: Unijuí.

RECEBIDO EM: 03/01/2019

APROVADO EM: 08/04/2020 